\title{
NOVELA, CINE (TV) Y VIDEOJUEGOS: EL NOMBRE DE LA ROSA Y LOS PILARES DE LA TIERRA
}

\author{
Juan Francisco JIMÉNEZ-ALCÁZAR
}

Universidad de Murcia

Gerardo F. RODRÍGUEZ ${ }^{3}$

Universidad Nacional de Mar del Plata

"Quien no juega a videojuegos se pierde un mundo fascinante" Álex de la Iglesia, director de cine

\section{RESUMEN}

En este estudio pretendemos abordar las adaptaciones que se han realizado de los éxitos literarios El nombre de la rosa, de Umberto Eco, y de Los Pilares de la Tierra, de Ken Follet, en el ámbito de los videojuegos, muy mediatizados por las producciones que existen de las dos en el cine y como serie de televisión respectivamente. El resultado de cómo se han plasmado en los distintos títulos hechos por diversos estudios de desarrollo de videojuego responde a los mismos criterios que lo hicieron quienes se decidieron a acomodar las excelentes historias, ambientadas en la Edad Media. La iconografía de lo que entendemos como "medieval" enmarca todas esas adaptaciones a la demanda de lo que los espectadores y usuarios esperan encontrarse, tanto si el resultado final sigue o no de forma escrupulosa lo contenido en las novelas objeto del estudio.

Palabras clave: Umberto Eco, Ken Follet, videojuegos, novela histórica, cine, televisión, Edad Media.

1 Este trabajo se inscribe en el seno del proyecto de investigación Historia y videojuegos (II): conocimiento, aprendizaje y proyección del pasado en la sociedad digital (HAR2016-78147-P), financiado por el Ministerio de Economía y Competitividad, Plan Estatal de Investigación Científica y Técnica y de Innovación 2013-2016, convocatoria de Excelencia 2016. www.historiayvideojuegos.com.

2 Dpto. Prehistoria, Arqueología, Historia Antigua, Historia Medieval y CCTTHH. Universidad de Murcia. c/ Santo Cristo, 1. 30001 Murcia (España). Correo electrónico: jimenezalcazar@um.es. ORCID: https://orcid. org/0000-0002-0934-2774.

3 Facultad de Humanidades. Universidad Nacional de Mar del Plata. Funes 3350. 7600 Mar del Plata, Buenos Aires (Argentina). Correo electrónico: gefarodriguez@gmail.com. ORCID: https://orcid.org/0000-00028251-4616. 


\section{ABSTRACT}

In this study we intend to address the adaptations that have been made of the literary successes The name of the rose, by Umberto Eco, and The Pillars of the Earth, by Ken Follet, in the field of video games, very mediated by the productions that they exist of both in the cinema and as a series of television respectively. The result of how they have been embodied in the different titles made by various video game development studies responds to the same criteria as those who decided to accommodate the excellent stories, set in the Middle Ages. The iconography of what we understand as "medieval" frames all those adaptations to the demand of what viewers and users expect to find, whether the final result follows or not scrupulously what is contained in the novels analyzed.

Keywords: Umberto Eco, Ken Follet, video games, historical novel, cinema, television, Middle Ages.

\section{INTRODUCCIÓN}

Siempre hemos considerado que un historiador es una mala compañía para ir a ver una película ambientada en un pasado histórico, sea cual sea la época, o, peor aún, la de un historiador en formación. Desde el clásico "esto no era así" al "vestían de otra manera", pasando por "en ese tiempo aún no existía tal cosa", el acompañante termina con un hartazgo lógico, pues lo que pretendía era, sencillamente, ver una película y no un documental. Sabemos que los géneros en nada se parecen, pero el visionado hace que las comparaciones sean inevitables. La novela histórica tiene unas connotaciones similares, aunque la diferencia radica en que la lectura se realiza de forma muy individualizada, con la excepción de que se haga bajo una fórmula de lectura colectiva y debate posterior, hecho más común cuando se trata de una producción cinematográfica. No es extraño que en las últimas décadas, justo cuando los medios tecnológicos lo han permitido, se haga este tipo de debates sobre cine histórico en las universidades, con análisis científico muy sólido por parte de historiadores e historiadores del cine. Este mismo marco de publicación es una muestra de ello.

Desde el mismo momento en que se aborda un estudio de carácter histórico sobre los aspectos contenidos en un producto de expresión cultural que no tiene un origen científico, leamos novela, cine o televisión, asaltan dudas de todo tipo ante la posibilidad de que se incurra en graves defectos de forma: el trato somero y simplista de algún tema que necesariamente precise de una detenida reflexión o de cualquier otra cuestión tangencial al propio análisis de la comprensión del pasado, se califica como auténtico desastre para el historiador. De una vez por todas, hay que ubicar cada producto en su ámbito, sin que haya por parte de quien escribe una obra literaria o un guion televisivo otro objetivo que el de gestar una obra de ficción, con todos los recursos a su alcance para lograr un resultado final de su agrado; otra cosa distinta es la recepción que tengan los lectores y espectadores de esa labor.

Pero una cuestión diferente es que no se puede discutir que esas producciones terminan, en diferentes grados, por influir en la iconografía mental que se genera entre el público de esos periodos históricos recreados. Se genera así el tópico, que vertebra a su vez cierta demanda de esos usuarios que esperan ver y leer algo que ya "conocen". 
En los casos en que el historiador realiza un análisis de determinado título cinematográfico con guion histórico, o un estudio de cualquier novela histórica o, de forma más reciente, de los videojuegos con trasfondo iconográfico o desarrollo ambientado en algún periodo pretérito, hay que tener en cuenta esa premisa, so pena de caer en el riesgo de convertirse en un censor de la ficción y, en último término, del creativo. Por lo tanto, no es sencillo, aunque lo parezca, realizar este tipo de estudios. Encima, si lo que pretendemos es hacer un enfoque que contemple la posibilidad de contar con tres ámbitos a la vez, el del cine, la novela y el videojuego, con la referencia común de un solo contenido, en este caso coincidente en que se trata de novelas originarias con repercusión en el cine y la televisión y en el videojuego, la empresa no es pequeña, y con ella, la ampliación de sus riesgos.

Por lo tanto, pretendemos exponer en este estudio un análisis sobre la adaptación de dos novelas con gran éxito editorial, y que podríamos considerar "clásicos" (aun a riesgo de estar sometido el aserto a matices varios), ya no tanto al cine o a la televisión, sino con la implicación del videojuego, que tiene sus correspondientes títulos sobre ambas obras. Nos referimos a Los Pilares de la Tierra, de Ken Follet, y a El nombre de la rosa, de Umberto Eco, las dos ambientadas en el periodo medieval aunque con un carácter completamente diverso tanto por la narrativa, como por el espacio geográfico y temporal en el que se desarrolla la trama, así como por el propio significado de las novelas en sí mismas.

No pretendemos realizar un estudio exhaustivo de cada una de las novelas, producción cinematográfica, serie de televisión y videojuegos, pues nos llevaría para cada una de ellas, juntas o por separado, muchas más páginas que las que les vamos a dedicar en este trabajo. Se trata, pues, de un acercamiento al fenómeno de esta conjunción de canales de comunicación y expresión cultural con la idea de profundizar en él mediante la incorporación de otros títulos y de otras obras en futuros trabajos.

\section{EL MEDIEVO: BASE DE GUIONES}

Procede aclarar que el análisis que realizamos en este estudio se basa en exclusiva en dos novelas con acontecimientos ambientados en el periodo medieval, como hemos especificado con anterioridad, en diversos territorios y en momentos distintos. Esos contextos van a llevar aparejados que los escenarios e incluso los personajes sean muy diferentes. Pero lo interesante es que se aglutinan en lo que reconocemos como Edad Media, y que de forma genérica desde el Renacimiento se identifica como el periodo que se prolonga desde los siglos V-VIII, aproximadamente, hasta los XV-XVI; esta laxitud en la delimitación temporal ya nos da una idea de lo que tenemos como concepto de "lo medieval". En esa etapa tan dilatada dará tiempo a observar mundos y civilizaciones de lo más diverso, pero que se simplifican en nuestra imagen colectiva de ese Medievo, hecho que ya advertía Delogu (1994: 72) hace algunos años, pero que tenemos muy claro todos los medievalistas. Un gran templo, con el todopoderoso estamento eclesiástico y sus estructuras, las vestimentas de monjes y frailes (estos últimos no aparecen aún, lógicamente, en Los Pilares de la Tierra), alimentación, acción y reacción ante una cultura por completo dominada por la religión, el papel de la mujer... son solo algunos de los numerosos elementos usados por ambos creadores para enmarcar sus tramas.

Las razones por la que el periodo medieval resulta tan "fascinante y atractivo" (González Jiménez, 2009: 55) para nuestra civilización son múltiples, proceso que para Occidente se retrotrae al movimiento romántico y forma parte de su esencia ( $\left.D^{\prime} A r c e n s, 2016\right)$. Pero 
centrados en las últimas décadas, solo cabe aludir a que se rescatan mundos perdidos que permanecen inalterables en la iconografía de lo que define la cultura occidental, sin entrar en más detalles que llevarían a objetivos bien distintos a los pretendidos en este trabajo. Estudios profusos y reflexiones sobre esta cuestión no son nuevos y tienen cierta tradición, como el de J. Heers (1995) o el de R. Pernoud (2010). Pero queremos centrarnos en ese reflejo sobre la producción literaria que tiene como referente indiscutible a sir Walter Scott y sus obras sobre el periodo Plantagenet anglosajón, que tuvo en todos los territorios europeos su correspondiente ejemplo. Es cierto también que en las últimas décadas hemos asistido a una eclosión de "novelas históricas" y de fenómenos literarios de enorme éxito editorial que condimentan sus tramas con elementos históricos, legendarios o no. G.R.R. Martin recurre a diversos elementos históricos en Juego de Tronos (Larrington, 2017), aunque, llegado el caso, habría que aludir a Tolkien como inspirador de estas obras que terminan por configurar una cultura propia con su particular fenómeno fan. La novela histórica "medieval", sin duda alguna, ha sido uno de los subgéneros de mayor éxito; la razón hay que buscarla en la demanda de esa sociedad, que pretende consumir títulos de ese periodo histórico en concreto, ayudada por determinadas obras que consolidaron la posibilidad de esa oferta por parte de los creadores: M. Drouon y sus Reyes Malditos, U. Eco y El nombre de la rosa y K. Follet y sus Pilares de la Tierra son auténticos referentes para todo lo que ha venido después.

Cuando en los 80 se adapta por J.J. Annaud la novela de Eco para el ámbito cinematográfico (1986), tenía un reto ante sí, pues se trataba de plasmar una obra maestra en un entorno que tenía ciertas reglas en aquella década (y aún hoy día para determinados públicos). En palabras de García Marsilla y Ortiz Villeta: "La adaptación cinematográfica de la exitosa novela de Umberto Eco conlleva no pocos riesgos. El principal tiene que ver con los varios niveles de lectura que ofrece" (2017: 146). Son numerosos los estudios sobre las múltiples aristas que tiene la novela, desde el jurídico (Muñoz de Baena y Simón, 1984; Obarrio Moreno, 2016) y filosófico (García Matarranz, 1987; Jáuregui, 1990; Camilo Corti, 2016) hasta la perspectiva pedagógica de la obra literaria para el historiador (Amores y Carrasco, 2014), referencias elegidas entre un sinfín de producciones científicas. En los créditos de la película aparece como asesor histórico un medievalista de la talla de J. Le Goff, pero la producción en sí misma vino a complicar aún más esos ángulos desde donde abordar la obra5.

La cuestión de las adaptaciones de novelas se complicó en el mismo momento en que la televisión precisó de todo tipo de producciones con el fin de completar parrillas de programación. Es cierto que en los últimos años vivimos una auténtica fiebre de las series para este formato (Grandío Pérez, 2016), ayudada por la multiplicación de las posibilidades de visionado, donde la potencia de la tecnología digital y la revolución de las comunicaciones han hecho el resto. En este contexto le llegó el turno a Los Pilares de la Tierra, de Ken Follet, aunque a diferencia de U. Eco, el autor británico estaba predispuesto desde el primer momento a colaborar con este tipo de iniciativas, cuestión que no solo podemos

4 Para la cuestión en su conjunto, véase Abad Ruiz, B.: "Transmedia y fenómeno fan: la co-creación en el mundo del videojuego", en J.F. Jiménez, Í. Mugueta y G. Rodríguez (coords.), Historia y videojuegos: el impacto de los nuevos medios de ocio sobre el conocimiento histórico, Murcia, CEM, 2016, pp. 69-103.

5 Analizada de manera profusa, hay que aludir a las páginas que le dedican a la película J.J. Alonso, E. Álvarez y J. Alonso en: La Edad Media en el cine, Madrid, T\&B, 2007, pp. 17-39. Y son muy aclaratorias las notas que recogen J.V. Marsilla y Á. Ortiz sobre el mismo film: Del castillo al plató. 50 miradas de cine sobre la Edad Media, Barcelona, UOC, 2017, pp. 146-148.

Quaderns, 13 (2018), pp. 49-62 


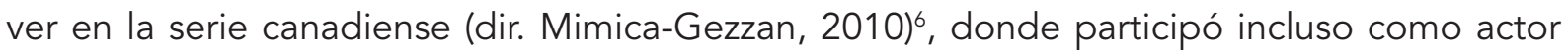
con un breve cameo al más puro estilo Hitchcock, sino también en el videojuego sobre su novela como mencionaremos más adelante. Ha tenido esta novela menos estudios de corte histórico que El nombre de la rosa, aunque contamos con algunos de mucho interés, como el de Bueno Domínguez (2009) o el de Porrinas González (2016), centrados el primero en los escenarios y el segundo en cómo refleja Follet el fenómeno de la guerra y la caballería en su obra.

En ambos casos, El nombre de la rosa y Los Pilares de la Tierra, se trata de adaptaciones, no podemos olvidarlo, pues las limitaciones y posibilidades de novela, cine y televisión en muchos casos son tan particulares que hacen imposible llevar a cabo la reproducción total, y eso que el uso de las tecnologías digitales ha facilitado -y abaratado- enormemente la reconstrucción de muchos escenarios. Por poner un ejemplo, el límite temporal de la producción cinematográfica no se corresponde con las posibilidades de una miniserie.

Una vez tenemos las novelas, la película y la serie de televisión, esas mismas adaptaciones vinieron a trastocarlo todo, ahora incluimos a las producciones citadas, pero desde la expresión del videojuego.

\section{EL VIDEOJUEGO HISTÓRICO}

El videojuego irrumpe en el universo de la expresión cultural de las más diversas formas. Una de ellas se manifiesta a través de la transmisión de contenidos históricos por medio de guiones que están basados en sucesos, iconografía, secuencias y tópicos de periodos pretéritos, como en el caso de novelas, películas y series de televisión enmarcadas en épocas pasadas. Los podemos identificar claramente por esa encarnación de modelos repetidos: un castillo medieval, un foro romano o un palacio barroco. Cuando el equipo de desarrollo del videojuego -guionista, ingeniero informático o artista gráfico- se pone de acuerdo para realizar un producto de estas características, lo hace con la misma pretensión que los demás creadores y profesionales técnicos. Pero como en el cine, la literatura y el medio televisivo, hay muchos tipos de videojuegos. Es más: la complicación viene dada por la misma idiosincrasia del canal. La interacción e intervención del usuario como participante del producto final hace que no solo haya diferencias en los contenidos o enfoque de la narrativa del videojuego ${ }^{7}$, sino en la manera de jugarlos según el género del título. No se juega igual a una aventura gráfica que a un arcade, uno de estrategia, de simulación, de plataforma, de puzle, etc., pero lo que sí los iguala es el trasfondo audiovisual y de contexto, en el sentido más estricto y literario del término. De esta manera, hay que señalar que el videojuego histórico, entendido como aquel que cumple las cuatro características básicas que lo definen: veracidad, verosimilitud, información y libertad para jugarlo (Jiménez Alcázar, 2018: 158-160), es lo que hace que nos fijemos en ellos como historiadores. La elección de

6 John Pielmeier contó con la colaboración del guion definitivo con K. Follet, y el productor John Ryan encontró una colaboración inestimable de Ridley Scott y Tony Scott como productores ejecutivos para esta serie destinada a The Movie Network. Los ocho capítulos de la serie contaron con actores de la talla de Matthew Macfadyen, Ian McShane, Rufus Sewell, Eddie Redmayne, Hayley Atwell o el incombustible Donald Sutherland. En España fue proyectada por el canal Cuatro, de Mediaset, aunque se ha podido localizar en diversos canales específicos como Movistar+. Se comercializó también en formato DVD y Blue-Ray.

7 Son muy interesante las reflexiones a este respecto de I. Martín Rodríguez: Análisis narrativo del guion de videojuego, Madrid, Síntesis-Editorial de la Universidad de Granada, 2015. 


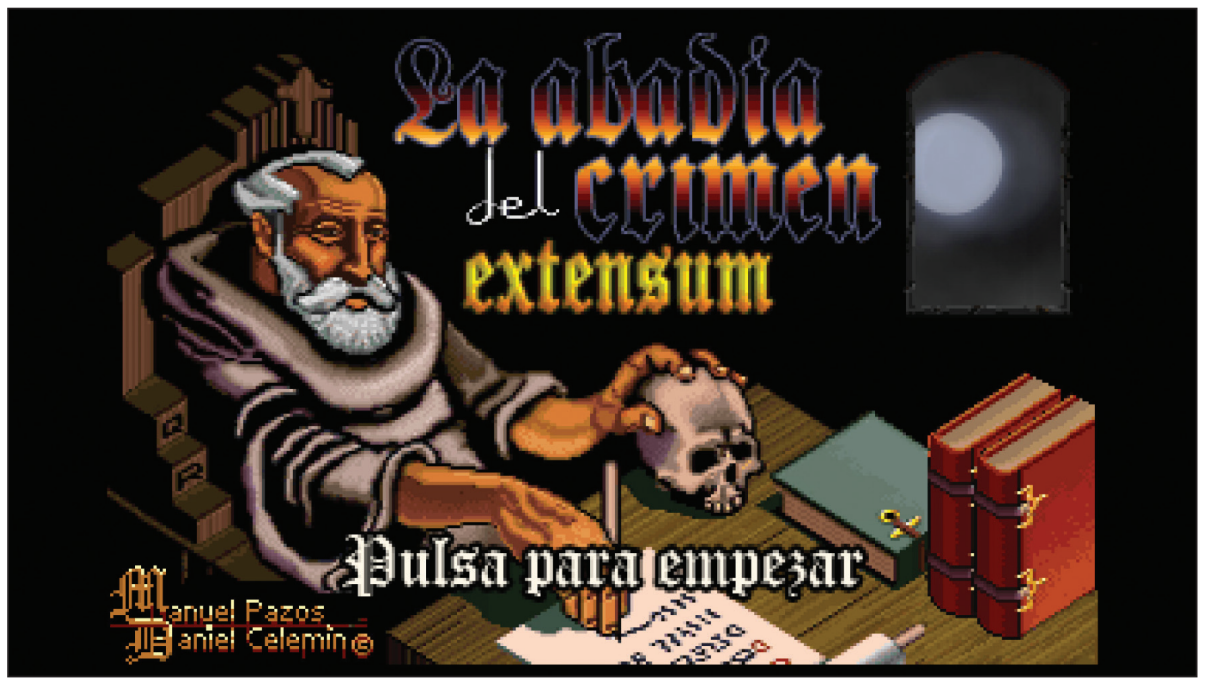

La Abadía del Crimen. Inicio de partida.

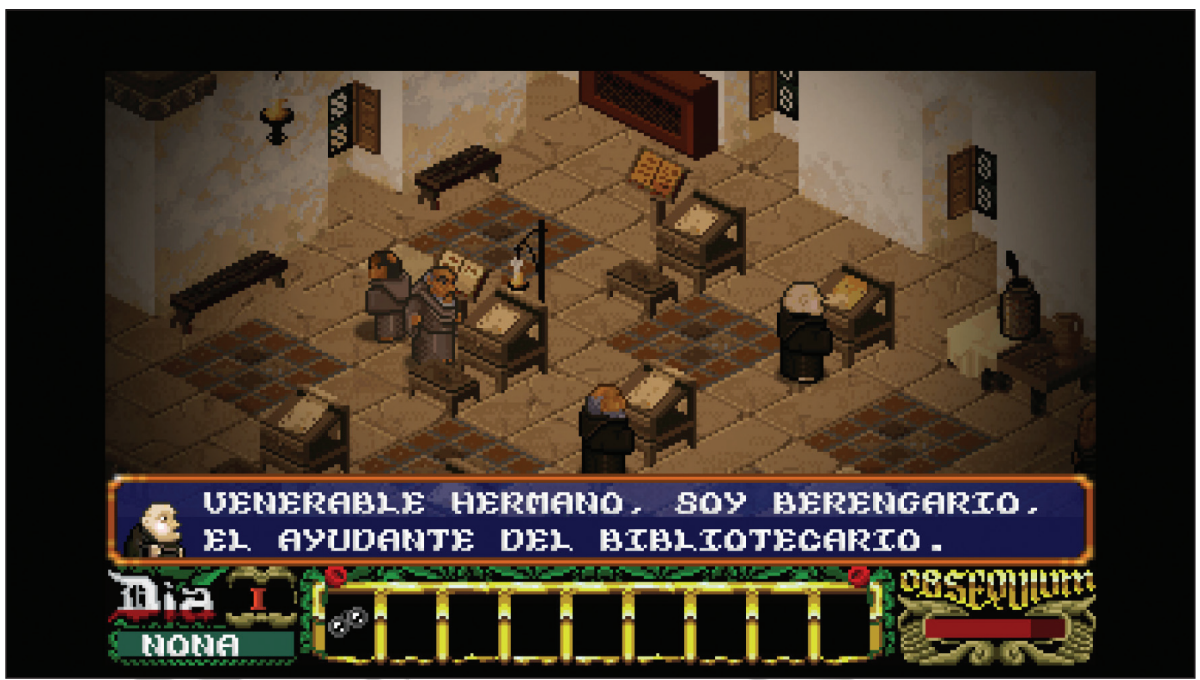

Guillermo de Occam en la biblioteca. La Abadía del Crimen.

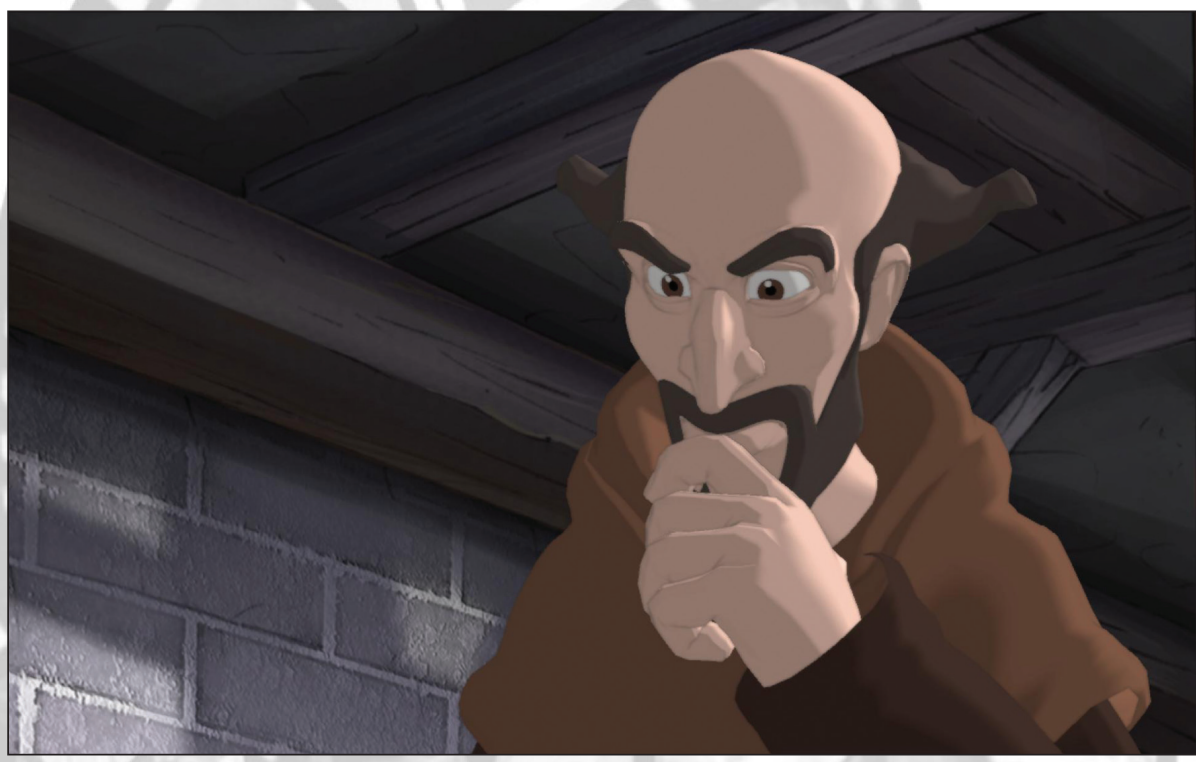

Leonardo de Toledo. The Abbey.

Quaderns, 13 (2018), pp. 49-62 


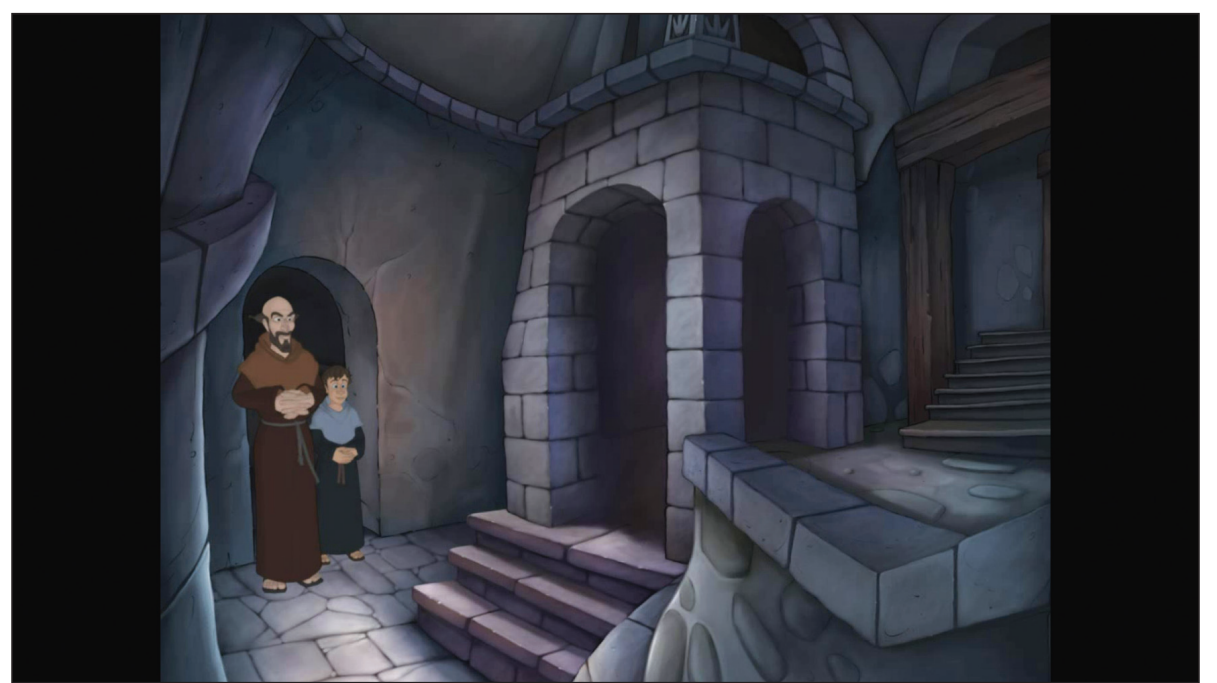

Leonardo de Toledo y Bruno en el laberinto de la biblioteca del monasterio. The Abbey.

un periodo histórico, o sus tópicos, para enmarcar un guion en el que desarrollar un juego, es muy interesante de abordar por cuanto nos indica nuestras preferencias culturales en muchos casos. El asunto se complica cuando se trata de adaptar una obra que tiene una imagen previa ya conocida -el usuario sabe de qué va, incluso su final-, con un periodo histórico de por medio, y con una historia definida. La Edad Media, con un trasfondo de infinitas posibilidades de desarrollo de historias e imágenes, se convierte así en una de las etapas preferidas por los creadores de videojuegos que cubren la creciente demanda de estos productos por los usuarios. Abordado el tema en otras ocasiones, ${ }^{8}$, ahora nos disponemos a mirar por un caleidoscopio que genera aún más aristas al tema.

Ya no se trata de analizar el resultado de la adaptación de una novela al cine o viceversa, sino de observar el resultado de novela y su ajuste cinematográfico o televisivo a un título de videojuego, donde el usuario parte de una serie de prejuicios, valores adquiridos e iconografía visual que tiene que acomodar al producto con el que va a "desarrollar" una historia que ya ha leído o que previamente ha visto.

Para los casos que nos ocupan, vamos a poner nuestro objetivo sobre tres títulos que están inspirados en las dos novelas escogidas: La abadía del crimen (Opera Soft, 1987), The Abbey (Alcachofa Soft, 2008) y Los Pilares de la Tierra (Daedalic Entertainment, 2017-2018).

\section{A) EL NOMBRE DE LA ROSA EN EL PC: LA ABADÍA DEL CRIMEN Y THE ABBEY}

Estos dos títulos desarrollados ambos por empresas españolas, supusieron un hito en sí mismos para el universo del videojuego, sobre todo el de Paco Menéndez y Delcán, hecho que le hizo merecedor de que el Servicio de Correos español editase un sello postal como reconocimiento9. La abadía del crimen, cuando apareció en el mercado allá por 1987 de mano de la Academia Míster Chip, aunque adquiridos sus derechos dos años después por

8 Jiménez Alcázar, J.F., De la Edad de los Imperios a la Guerra Total: Medievo y videojuegos, Murcia, CEM, 2016. Descargable en: http://www.historiayvideojuegos.com/?q=node/165.

9 Todos los detalles sobre la emisión del sello en: https://www.correos.es/ss/Satellite/site/coleccion1363198143150-galeria_sellos_filatelia/detalle_emision-sidioma=es_ES 
Opera Soft, supuso un punto de referencia para los profesionales del desarrollo y para los usuarios. Se podía jugar en Sinclair ZX Spectrum, MSX, Amstrad CPC, Windows, DOS y GNU/Linux ${ }^{10}$, por lo que su difusión fue alta a pesar de que no tuvo un gran éxito comercial. No obstante, y sobre todo con la eclosión del fenómeno retro ${ }^{11}$, el juego se convirtió en un clásico, tanto que se volvió a publicar mejorado en 2016 como La abadía del crimen Extensum $^{12}$, en este caso con incorporaciones claras del elemento cinematográfico de J.J. Annaud, tal y como se especifica en los créditos. Basado en la novela de Eco, tiene una adaptación diversa, pero respetando ambiente y contenidos en su mayor parte. Este hecho es la gran diferencia con el título de Alcachofa Soft, The Abbey, pues no recurre a elementos propios y esenciales de la novela como su contexto histórico, sino que construye su guion particular a raíz de la inspiración de la obra del estudioso italiano, tal y como aparece en los créditos del videojuego: sí, es un monasterio, un maestro y su discípulo, pero hasta ahí la coincidencia. La aventura gráfica navega desde el comienzo por unos derroteros completamente distintos a los de El nombre de la rosa, donde el referente es una abadía -en este caso será en el solar hispánico y no italiano-, su biblioteca, un misterio que resolver y un personaje central, Leonardo de Toledo, que bebe en las raíces de Guillermo de Baskerville, incluso en su aspecto inspirado en el actor que lo interpretó en la película, Sean Connery. Se publicó en 2008 para PC, distribuido por Friendware, pero no nació como remake de La abadía del crimen sino más bien como un homenaje al videojuego clásico y a la propia novela ${ }^{13}$. Si bien el título de Menéndez y Delcán hundía su diseño en una perspectiva isométrica con píxeles vistos por las posibilidades tecnológicas de 1987, en el caso de The Abbey es el dibujo de animación el que hace de este videojuego una auténtica obra de arte gráfica en cada una de las secuencias y en el tratamiento de cada uno de sus personajes. Las apuestas cinemáticas del título forman parte esencial del mismo, por lo que llegamos finalmente al desenlace de la historia muy tutorizados por los desarrolladores. E. García alude a la "verdadera experiencia cinematográfica interactiva" de este juego ${ }^{14}$, aserto que compartimos sin duda alguna.

\section{B) LOS PILARES DE LA TIERRA EN MULTIPLATAFORMA}

De la mano del estudio alemán Daedalic Entertainment, en el verano de 2017 salió comercializado el videojuego que adapta la novela de Ken Follet, y que se completó en marzo de 2018 con el estreno de la última parte, descargable de forma gratuita para los usuarios que ya habían adquirido el título en ese lapso de tiempo. Para PC, PS4 y Xbox One $y$, de momento, en la Apple Store, el juego utiliza como base gráfica unos excepcionales dibujos realizados por el equipo de artistas que dan una personalidad al videojuego que cualquier usuario sabrá apreciar; es un juicio de valor, pero para un medievalista es una auténtica delicia ver los escenarios de la Inglaterra, Francia y Castilla del siglo XII. Es

10 Datos extraídos de: https://es.wikipedia.org/wiki/La_abadía_del_crimen.

11 Sobre el juego, es obligada la referencia del libro de Esteve, J. (coord.), Obsequium: un relato cultural, tecnológico y emocional de "La Abadía del Crimen», Barcelona, 2014.

12 Con mejoras de Manuel Pazos, Antonio Giner y Daniel Celemín. Se puede descargar el juego en http:// www.abadiadelcrimenextensum.com/el-juego/, así como en la plataforma Steam.

13 García, E., "Hombres de Dios", Meristation, 24 noviembre 2008. http://meristation.as.com/pc/theabbey/analisis-juego/1521916.

14 Ibídem.

Quaderns, 13 (2018), pp. 49-62 


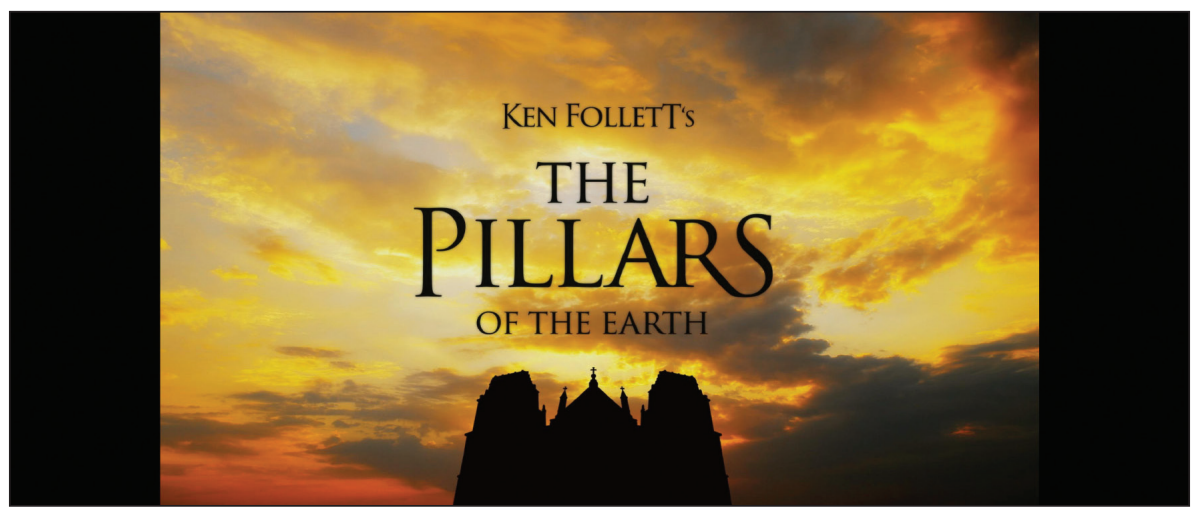

Los Pilares de la Tierra. Inicio de partida.

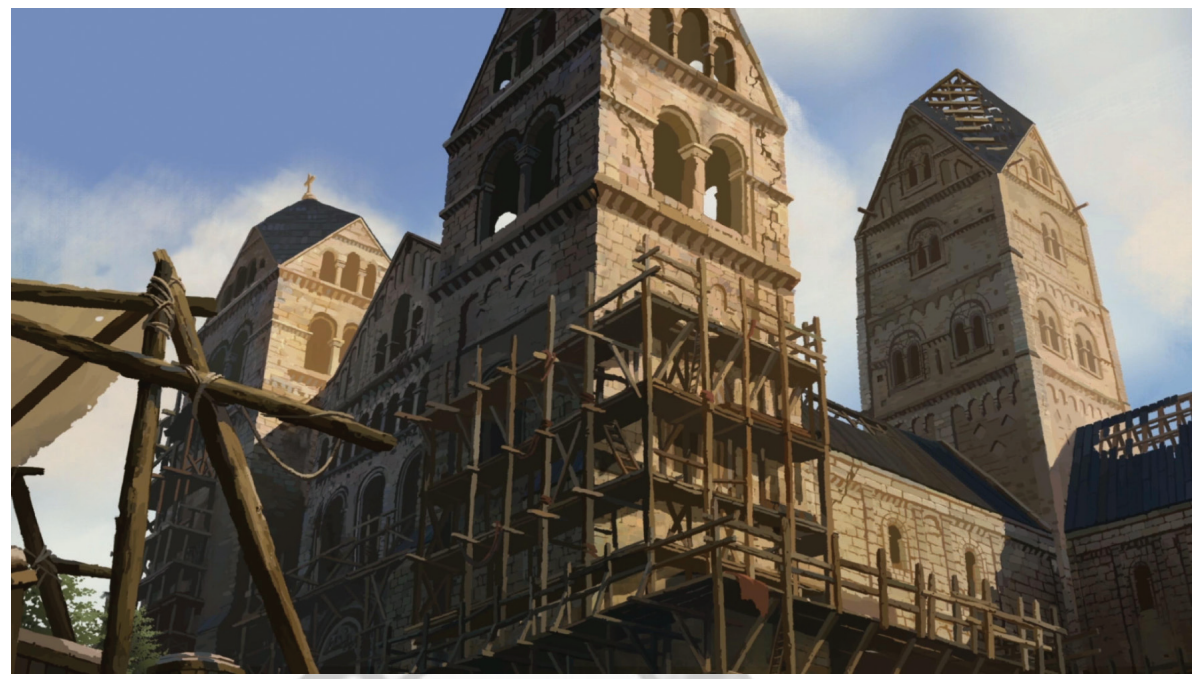

La catedral de Kingsbridge en construcción. Los Pilares de la Tierra.

una aventura gráfica point \& click en dos dimensiones que permite seguir la novela de manera interactiva, ya que los momentos cinemáticos son numerosos y te acompañan hasta completar los tres "libros" con sus respectivos siete capítulos que componen cada uno de ellos, para concluir con un final acorde con el deseo original del narrador inglés, que, al contrario que en el caso de Umberto Eco, aquí también colabora como ya lo hizo en la serie de televisión sobre su novela, tal y como hemos aludido con anterioridad. La banda sonora, incluida en la edición coleccionista, acompaña perfectamente al desarrollo de la trama ${ }^{15}, y$ es parte esencial de su calidad final.

\section{EL FENÓMENO DEL CROSSMEDIA: LECTOR, ESPECTADOR (TELESPECTADOR) Y USUARIO}

En absoluto descubrimos nada nuevo con la cuestión de las adaptaciones, pues es la novela llevada al cine, o la ficción televisiva novelada. Es el fenómeno crossmedia en su

15 En un trabajo previo abordamos la importancia del sonido y las bandas sonoras en los videojuegos históricos: Jiménez Alcázar, J.F. y Rodríguez, G.: "Medieval Soundspace in the New Digital Leisure Time Media", Imago Temporis, 9 (2015), pp. 305-323. 
sentido más literal. Hay que diferenciarlo con el de transmedia ${ }^{16}$ (Scolari, 2013) donde no se limita a la acomodación de un guion concreto en un medio diferente al original, sino a la generación de un argumento básico que tendrá reflejo en diversos medios y con diferentes expresiones culturales: cine, novela, cómic, videojuego, pintura, escultura... enmarcado todo en el deseo del usuario final por "tener" parte de ese producto en su poder: es la clave de la mercadotecnia. Difícilmente tendría explicación el anhelo de tener sobre nuestra estantería una figurita de un asesino si no se tratase de Altaïr, Ezio o cualquiera de los protagonistas de la saga de Assassin's Creed (Ubisoft, desde 2007), héroes para una legión de videojugadores.

En el caso que nos ocupa, el trasfondo es ciertamente complicado, pues se trata de adaptaciones al entorno del videojuego que ya tiene de forma previa una acomodación a un medio audiovisual: un actor ya le pone "cara" a un personaje, y el espectador es muy posible que espere ver en su videojuego a alguien que se asemeje a lo que ya conoce, como si se tratase del resto de tópicos, en este caso medievales, que ve y oye.

Los dos casos que tratamos basan su resultado en un proceso de lo que podríamos denominar cross-crossmedia, ya que se ha tratado de un puente con dos ojos, pues es posible que muchos usuarios hayan tenido conocimiento de la obra de Eco o de la de Follet a través de la película o serie de televisión y no del libro, siendo cada una de esas expresiones culturales uno de esos ojos hasta llegar al resultado final del videojuego. Por ejemplo, tenemos el caso de Indiana Jones y la última cruzada, donde el referente de la película (S. Spielberg, 1989) era una guía para el videojugador, pero que el propio juego (LucasArts, 1989) ampliaba los horizontes característicos del espectador, y el usuario cobraba protagonismo de los vaivenes de la historia. Y ahí acaba la experiencia. Para El nombre de la rosa y Los Pilares de la Tierra es esa complicación la que nos atrae y hace interesante para el análisis.

Las adaptaciones al videojuego se producen así, desde dos vías, con la conjunción de ambas y con resultados que en ninguno de los tres casos son coincidentes en sus reflejos para la experiencia de juego. La obra del escritor inglés, muy centrada en el desarrollo y evolución de los personajes, conserva en los diversos capítulos de la serie y en el videojuego esa característica. La diferencia con los remakes de la obra de Eco es que la diversidad de planos y niveles de lectura hacen que sea mucho más complicada, pero en absoluto quiere decir que las de Follet hayan sido más sencillas. De hecho, pensamos que era mucho más difícil, ya que el usuario, tanto si ha leído como si ha visto la novela o la serie, espera que cada personaje responda según se definieron en origen. La web oficial del juego así lo deja ver: "Play as Jack, Aliena and Philip and change the events of the book through exploration, decision-making and dialogues"17. El deseo de los desarrolladores, al contrario que con los títulos inspirados en El nombre de la rosa, era precisamente contar la novela en otro canal de expresión: "Los Pilares de la Tierra busca, ante todo, contarnos la fabulosa historia que el escritor británico plasmó hace casi treinta años. Lo cierto es que lo logra, y no con

16 Recientemente han sido editadas unas actas producto de un congreso que tuvo lugar en la Universidad de Alicante sobre el fenómeno transmedia, y que están consultables online: Actas de las Jornadas Científicas Internacionales sobre Análisis del discurso en un entorno transmedia, J. Segarra-Saavedra, T. Hidalgo-Marí y R. Rodríguez-Ferrándiz (coords.), colección «Mundo Digital de Revista Mediterránea de Comunicación», Alicante, Universidad de Alicante, 2018. http://rua.ua.es/dspace/handle/10045/72791.

17 Web oficial del juego: http://www.the-pillars-of-the-earth-game.com/ 
pocos esfuerzos"18. Es evidente que una obra tan densa y extensa debía ser acomodada a los límites propios del videojuego, con una narrativa que hace de las escenas cinemáticas algo habitual para seguir la historia. Se sacrifican muchos contenidos, matices, personajes... pero al igual que la serie, el producto resultante complementa gratamente a quienes ya han leído o visto Los Pilares. Es la comprensión y experiencia de juego lo que convierte al título en una referencia para las producciones de videojuegos ambientados en el periodo medieval. Solamente Guillermo de Baskerville (El nombre de la rosa) - Guillermo de Occam (La Abadía del Crimen) - Leonardo de Toledo (The Abbey) puede asemejarse a alguno de los personajes principales de la adaptación anterior. Es posible que la participación de Follet en el desarrollo del videojuego tenga algo que ver en la gran adaptación, de la misma manera que lo hizo en la producción televisiva.

Es una manera diferente de disfrutar la historia creada por Ken Follet, sin que tenga que excluirse ninguno de los canales por donde lo hayamos visto-leído-jugado. Es la gran diferencia con la película y videojuegos de la obra de Umberto Eco, ya que mientras la película procura la adaptación, con la adecuación al límite cinematográfico de Annaud, El crimen de la abadía y The Abbey solo tienen a El nombre de la rosa como inspiración, y en estos casos con la mixtura iconográfica resultado de la película previa.

\section{CONCLUSIONES}

Una buena "historia" (story) vemos que tiene un valor potencial enorme. Qué duda cabe que una buena "historia" (history) es el resultado de una labor metodológica y científica y es necesaria para el análisis y comprensión de las civilizaciones del pasado. Cuando la fusión se produce en el marco de un producto cultural, tanto si se realiza como medio de expresión o como un objetivo de difusión, las posibilidades se dibujan sin límites.

Si hasta la fecha fueron numerosos los debates desde la perspectiva del historiador sobre el contenido de las novelas escogidas, y en su momento lo fueron acerca de la versión de Jean Jacques Annaud en el cine, la irrupción del videojuego como medio de expresión ha venido a alterar esa situación. No ha sido para desplazar esa óptica sino para complicarla y completarla. Junto al lector y espectador, hasta ahora factores pasivos en el resultado de las producciones, el usuario ha aparecido para quedarse. El videojuego se configura como un medio completo solo cuando es jugado, pues depende de las decisiones de quien lo juega para su resultado final; en realidad, es el carácter interactivo e inmersivo del elemento lo que lo define. Hemos llegado a oír en alguna de nuestras intervenciones públicas que el videojuego limita la imaginación con respecto la novela, porque se ve y se oye lo que en el texto se ha de construir mentalmente a través de las directrices que especifican las descripciones del autor. Pero son críticas que se le hacen al videojuego y no al cine. Como cuestión clara hemos de señalar que son comentarios que realiza quien no tiene un conocimiento claro de lo que es un videojuego, pues esa tarea creativa de escenarios y narrativas funciona de la misma manera que en el resto de productos culturales, pero con el factor inédito de la intervención necesaria del videojugador. En los dos casos analizados, la situación es más compleja por cuanto se trata de un guion ya establecido y con un desarrollo y final gestado previamente en las obras de Umberto Eco y Ken Follet. Las variantes que los

18 Pascual, A.: "Análisis de «Los Pilares de la Tierra», de best-seller a buen videojuego", 3djuegos, 30 de marzo de 2018. https://www.3djuegos.com/juegos/analisis/20861/0/los-pilares-de-la-tierra/ 
directores de la película de cine y serie televisiva han hecho para sus respectivas producciones, responden precisamente a su interpretación particular de la novela previa. Las versiones que vemos en los títulos de los videojuegos referidos a las novelas originales tienen aún un giro de tuerca más, pues las interpretaciones de los desarrolladores incorporan, en el caso de El nombre de la rosa, elementos claros y referencias evidentes del producto cinematográfico debido sobre todo al éxito de la película de Annaud. El caso de Los Pilares de la Tierra bebe directamente de las descripciones de la obra y, de hecho y como contrapunto al resultado de La abadía del crimen y The Abbey, es una acomodación de la novela. Si queremos conocer la novela de Follet, el videojuego es un medio excepcional, mientras que para el caso de la de Eco son incitaciones para ello.

En definitiva, y como conclusión final, todas las producciones aludidas en este estudio han generado una iconografía específica del periodo medieval para un público generalista. No hay duda alguna en el resultado de divulgación que tuvieron ambas novelas, y tampoco ha sido sorprendente su adaptación al medio cinematográfico y televisivo, tal y como lo es en la actualidad La Catedral del Mar de Ildefonso Falcones en una serie producida por Atresmedia y Televisió de Catalunya. Pero como resultado visible del mundo en el que nos desenvolvemos, las inspiraciones y adaptaciones al universo del videojuego muestran claramente la vitalidad de ambas obras, tanto por su propia calidad narrativa como por la demanda de producciones ambientadas en el Medievo, que es lo que en último término nos afecta a la hora de enfrentarnos desde la disciplina a la imagen colectiva de la Edad Media.

\section{BIBLIOGRAFÍA CITADA}

Abad Ruiz, B., "Transmedia y fenómeno fan: la co-creación en el mundo del videojuego", en J.F. Jiménez, Í. Mugueta y G. Rodríguez (coords.), Historia y videojuegos: el impacto de los nuevos medios de ocio sobre el conocimiento histórico, Murcia, CEM, 2016, pp. 69-103.

Alonso, J.J.; Álvarez Mastache, E. y Alonso, J., La Edad Media en el cine, Madrid, T\&B, 2007. Amores Bonilla, P.A. y Carrasco Bertomeu, J., "La literatura como fuente de información histórica: el dulcinismo en "El nombre de la rosa» y su contexto histórico", CLÍO, 40 (2014); <http://clio.rediris.es/n40/articulos/AmoresCarrasco2014.pdf> [consulta: 12 de junio de 2018].

Barrio Barrio, J.A., "La Edad media en el cine del siglo XX", Medievalismo, 5 (2005), pp. 241-268.

Barrio Barrio, J.A., "La Edad Media en el cine de Estados Unidos", Imago Temporis, 2 (2008), pp. $426-452$.

Bueno Domínguez, Ma L., "Los escenarios materiales en Los Pilares de la Tierra", en I. del Val y P. Martínez (coords.), Castilla y el mundo feudal: homenaje al profesor Valdeón, vol. 1, Valladolid, Universidad de Valladolid, 2009, pp. 147-159.

Camilo Corti, E., "Política y narración en El nombre de la rosa de Umberto Eco", Aporía: revista internacional de investigaciones filosóficas, Extra 1 (2016), pp. 71-90.

Corral Lafuente, J.L., "Novela y cine sobre la Edad Media: versiones abreviadas y discutibles de la historia", en E. López Ojeda (ed.), Nuevos temas, nuevas perspectivas en Historia Medieval, Logroño, Instituto de Estudios Riojanos, 2015, pp. 239-262.

D'Arcens, L., The Cambridge Companion to Medievalism, Cambridge, Cambridge University Press, 2016.

Quaderns, 13 (2018), pp. 49-62 
Delogu, P., Introduzione allo studio della Storia Medievale, Bolonia, Il Mulino, 1994.

Díez de Revenga Torres, F.J., "La Edad Media y la novela actual", Medievalismo, 3 (1993), pp. 69-83.

Esteve, J. (coord.), Obsequium: un relato cultural, tecnológico y emocional de «La Abadía del Crimen», Barcelona, Create Space Independent Publishing Platform, 2014.

García, E., "Hombres de Dios", Meristation, 24 (noviembre 2008); <http://meristation.as.com/ pc/the-abbey/analisis-juego/1521916> [consulta: 12 de junio de 2018].

García Marsilla, J.V. y Ortiz Villeta, Á., Del castillo al plató. 50 miradas de cine sobre la Edad Media, UOC, Barcelona, 2017.

García Matarranz, F., "Filosofía política medieval en «El nombre de la rosa»", Revista de Estudios Políticos, 56 (1987), pp. 137-158.

Garro, L., Viaggio in torno al concetto di Medioevo, Roma Bulzoni, 2002.

González Jiménez, M., "Percepción académica y social de la Edad Media. Un siglo de historia e historiadores", en La Historia medieval hoy: percepción académica y percepción social, XXV Semana de Estudios Medievales de Estella 2008, Pamplona, Publicaciones del Gobierno de Navarra, 2009, pp. 37-62.

Grandío Pérez, Ma M., Adictos a las series. 50 años de lecciones de los fans, Barcelona, UOC, 2006.

Heers, J., La invención de la Edad Media, Barcelona, Crítica, 1995.

Jáuregui, A., "Umberto Eco o la recreación del nominalismo en "El nombre de la rosa»", Folios: revista de la Facultad de Humanidades, 1 (1990); <http://revistas.pedagogica. edu.co/index.php/RF/article/view/5330/5212> [consulta: 12 de junio de 2018].

Jiménez Alcázar, J.F. y Rodríguez, G.: "Medieval Soundspace in the New Digital Leisure Time Media", Imago Temporis, 9 (2015), pp. 305-323.

Jiménez Alcázar, J.F., De la Edad de los Imperios a la Guerra Total: Medievo y videojuegos, Murcia, CEM, 2016.

Jiménez Alcázar, J.F., "La Historia vista a través de los videojuegos", en Juego y ocio en la Historia, Valladolid, Ediciones de la Universidad de Valladolid-Instituto Universitario de Historia «Simancas», 2018, pp. 141-170.

Larrington, C., Winter is coming. El mundo medieval en Juego de Tronos, Londres, Desperta Ferro Ediciones, 2017.

Martín Rodríguez, I., Análisis narrativo del guion de videojuego, Madrid, Síntesis-Editorial de la Universidad de Granada, 2015.

Martos Sánchez, J.L. y García Sempero, M. (eds.), L'Edat Mitjana en el cinema i en la novel·la histórica, Alicante, Inst. Filología Valenciana, 2009.

Muñoz de Baena y Simón, J.L., "El pensamiento iusnaturalista escolástico en «El nombre de la rosa»", La Ley: Revista jurídica española de doctrina, jurisprudencia y bibliografía, 3 (1984), pp. 843-849.

Muro Munilla, M.Á., "Guerras de celuloide y digitalización: la imagen de la guerra en el cine ambientado en la Edad Media (rasgos de un subgénero)", en B. Casado y J.I. de la Iglesia, La guerra en la Edad Media, Logroño, Instituto de Estudios Riojanos, 2006, pp. 221-266.

Obarrio Moreno, J.A., "El derecho medieval en El nombre de la rosa", Revista General de Derecho Romano, 27 (2016); http://www.iustel.com/v2/revistas/detalle_revista. asp?id=11\&numero=27 [consulta: 12 de junio de 2018]. 
Pascual, A, "Análisis de "Los Pilares de la Tierra», de best-seller a buen videojuego", 3djuegos,

(30 de marzo de 2018); <https://www.3djuegos.com/juegos/analisis/20861/0/los-pilaresde-la-tierra/> [consulta: 12 de junio de 2018].

Pernoud, R. [1977], Para acabar con la Edad Media, Barcelona, José de Olañeta, 2010.

Porrinas González, D., "Guerra y caballería en «Los Pilares de la Tierra» de Ken Follet", IntusLegere. Historia, 10-1 (2016), pp. 5-28.

Ruiz de la Peña Solar, J.I., Introducción al estudio de la Edad Media, Madrid, Siglo XXI, 1987.

Ruiz Domenec, J.E., "El poder de la ficción. La Edad Media vista por la novela histórica", en La Historia medieval hoy: percepción académica y percepción social, XXV Semana de Estudios Medievales de Estella 2008, Pamplona, Publicaciones del Gobierno de Navarra, 2009, pp. 247-261.

Sabaté i Curull, F. (coords.), L'Edat Mitjana. Món real i espai imaginat, Barcelona, Afers, 2012. Saitta, A., Guida critica alla storia medievale, Roma-Bari, Laterza, 1981.

Scolari, C.A., Narrativas transmedia. Cuando todos los medios cuentan, Barcelona, Centro Libros PAPF, 2013.

Segarra-Saavedra, J.; Hidalgo-Marí, T. y Rodríguez-Ferrándiz, R. (coords.), Actas de las Jornadas Científicas Internacionales sobre Análisis del discurso en un entorno transmedia, colección «Mundo Digital de Revista Mediterránea de Comunicación», Alicante, Universidad de Alicante (2018); <http://rua.ua.es/dspace/handle/10045/72791> [consulta: 12 de junio de 2018].

\section{ILUSTRACIONES}

(Fuente: Todas las imágenes corresponden a capturas de pantalla propias). 